coverage of grammar and vocabulary and requires considerable attention to detail. Answers are provided at the back of the book.

This book is highly recommended for international doctors as an accessible and clear guide to current English usage. It is very readable, well organised and could be used by both examination candidates as a workbook and by practising doctors as a reference guide to the innumerable idioms and colloquial expressions with which their patients may bombard them in the clinic.

\section{Cope's Early Diagnosis of the Acute Abdomen (21st edn)}

WILLIAM SILEN

\begin{tabular}{ll}
\hline EXTENT P/H & $298 \mathrm{p}$, paperback \\
PRICE/ISBN & $£ 19.99 \quad$ O195175468 \\
PUBLISHER & Oxford University Press (Oxford), 2005 \\
REVIEWER & Dominic Slade \\
STAR RATING & $* * *$
\end{tabular}

Zachary Cope published the first edition of this treatise on the diagnosis of the acute abdomen in 1921. From the outset, he emphasised the importance of personal experience and clinical observation, confirmed frequently by everyday practice in arriving at early and timely diagnoses. Eightyfour years later in this latest edition, Silen has remained true to Cope's key ideology.

The style is somewhat reminiscent of a grand master such as Goligher giving out useful tips gleaned from a lifetime's experience on an imaginary ward round. Unlike Goligher, the text is at times awkward and unnecessarily long-winded. Nevertheless, there is no doubting the author's dedication to his subject, including a description of Cope's own signs and symptoms during an attack of cholecystitis culminating in a laparotomy for a perforated gall bladder!

The book is aimed at the tyro dealing with the unselected general surgical 'take' and would form a useful reference in establishing a clinical diagnosis. Its layout includes the regular lists of differential diagnoses followed by a detailed explanation of how they differ from one another. For example, there is particular detail on how to differentiate intestinal obstruction from other abdominal catastrophes by careful attention to the nature, colour and frequency of vomiting. There are pearls of wisdom even for the experienced clinician and clear descriptions of clinical signs, such as liver resonance in perforated peptic ulceration, and how to determine abdominal pain of thoracic origin. Contained within its 26 chapters, there are useful sections covering the acute abdomen in pregnancy, the immunocompromised, patients with impaired sensation following injury and operation, as well as a discussion of those conditions that mimic abdominal disease. There are 16 black and white plates, predominantly of plain abdominal films, illustrative of the common conditions described in the text.

This book champions the skills of clinical diagnosis founded on the cornerstones of careful history taking and examination. Both Cope and Silen eschew the modern doctor's reliance on laboratory tests and cross-sectional imaging, constantly stressing that many diagnoses can be arrived at purely through careful attention to detail. This mantra is repeated throughout and bears an important message to all of us lazily reaching for the CT scan request card.

\section{Organisational Development in Healthcare: Approaches, Innovations, Achievements \\ EDWARD PECK}

\begin{tabular}{ll}
\hline EXTENT P/H & $376 \mathrm{p}$, paperback \\
PRICE/ISBN & $£ 35.00 \quad$ 185775896X \\
PUBLISHER & Radcliffe (Oxford), 2004 \\
REVIEWER & Ron Hopkins \\
STAR RATING & $* * *$
\end{tabular}

This book is a comprehensive academic study of organisational development with a strong NHS context. It will be a good resource book for staff working in human resources and organisational development. Its academic emphasis and concentration on theory does not produce an easy, everyday read for healthcare professionals who may be looking for simple understanding of organisational development that they can apply to daily practice.

The book is well researched and makes a good attempt to explain, in depth, organisational development from a theoretical and practical background. There are many useful pearls of wisdom scattered throughout and it is well referenced from both an organisational development and an NHS perspective. It would, however, be of benefit to the busy clinical manager to have examples of case studies on how some of the tools can be applied and lessons learned.

The final chapter is good and explains that, due to lack of empirical evidence to support any given methodology, 'no self-respecting academic would nail his view to the mast'.

The book outlines tools and approaches to organisational development that will prove useful but the style and approach in the text requires some tenacity to complete. Nevertheless, such tenacity is rewarded and real benefits can be derived from the book. Perhaps a more condensed and practical version could be produced for wider NHS use? 